\title{
Synthesis of Gold Nanoparticles in Aqueous Solutions by Electrochemical Reduction Using poly(ethylen glicol) as Stabilizer
}

\author{
Patricia Guadalupe Haro-González, Divino Salvador Ramírez-Rico, Erika Roxana Larios-Durán* \\ Universidad de Guadalajara. CUCEI. Departamento de Ingeniería Química, Blvd. M. García Barragán \\ \#1451, C. P. 44430, Guadalajara, Jalisco, Mexico. \\ *E-mail: roxlarios@icloud.com
}

doi: $10.20964 / 2019.10 .10$

Received: 17 May 2019 / Accepted: 23 July 2019 / Published: 30 August 2019

\begin{abstract}
A simple electrochemical method to produce gold nanoparticles (AuNPs) in aqueous media is presented. This method is based on the potentiostatic reduction of auric ions in the bulk of a potassium nitrate solution containing poly(ethylene glycol) $\left(\mathrm{PEG}_{20,000}\right)$ as a stabilizer. The electroreduction process is obtained when a negative polarization potential is applied to the system. To our knowledge, this is the first time that $\mathrm{PEG}_{20,000}$ is used as a stabilizer, and its influence on the synthesis of gold nanoparticles is examined. The analysis and characterization of the synthesized AuNPs by cyclic voltammetry, XRD and TEM is presented.
\end{abstract}

Keywords: Gold nanoparticles, electrochemical method, poly(ethylene glycol), electroreduction

\section{$\underline{\text { FULL TEXT }}$}

(C) 2019 The Authors. Published by ESG (www.electrochemsci.org). This article is an open access article distributed under the terms and conditions of the Creative Commons Attribution license (http://creativecommons.org/licenses/by/4.0/). 